Version of Record: https://www.sciencedirect.com/science/article/pii/S2110701718300180

Manuscript_77ccd7d19e86e 78fe003c7cbb6d5e80d

\title{
Exchange Rate Predictability In Emerging Markets*
}

\author{
Elisa Baku \\ Paris School of Economics, \\ Amundi Asset Management \\ \& University Paris 1 Pantheon Sorbonne \\ Elisa.Baku@etu.univ-paris1.fr \\ elisa.baku@amundi.com
}

June 2018

\begin{abstract}
This paper uses financial and macroeconomic variables to predict currency returns, by using a two-step procedure. The first step consists of a cointegration equation that explains the exchange rate level as a function of global and domestic financial factors. The second step estimates an error-correction equation, for modeling the expected returns. This approach is a factor model analysis, where a Lasso derived technique is used for variable selection. This paper will focus on the five most frequently traded Latin American currencies, Brazilian Real (BRL), Chilean Peso (CLP), Colombian Peso (COL), Mexican Peso (MXN) and Peruvian Sol (PEN), during the time horizon from December 2001 until February 2016. The first finding is that the Global Exchange Rate Factor offers information about the exchange rate movements. In addition, this paper shows that commodity, equity prices and domestic risk premium are important variables for explaining exchange rates. Moreover, it confirms the existing results for the carry and slope variables.
\end{abstract}

Keywords: Exchange Rates, Latin America Emerging Markets, Lasso, ErrorCorrection, Factor Model.

JEL classification: F31, C3, E44.

* views expressed in this paper are those of the author and do not necessarily reflect those of Amundi. The author is very grateful to Jean-Bernard Chatelain, Catherine Doz, Edmond Lezmi, Binh Phung-Que and Thierry Roncalli for their helpful comments and suggestions. 


\section{Introduction}

The relationship between exchange rates and financial, macroeconomic fundamentals remains a research question, even though extensive literature exists on the subject, dating back to the early 1970s at least. Nowadays, the direction of the research is toward a new methodology called the 'factor model'. In their paper, Engel et al. (2010) state:

[...] "exchange rates themselves have information that is hard to extract from observable fundamentals. This information might be hard to extract because standard measures of fundamentals (e.g. money supply and output) are error ridden, or because we simply lack any direct measures of non-standard fundamentals such as risk premia or noise trading".

They propose a principal component decomposition of exchange rates and use the components to predict the bilateral exchange rate. But some economists argue that by using principal component methodology one fails to report the share of common variation of each currency pair. Verdelhan (2017), meanwhile, focuses on two risk factors - carry and dollar - to provide a natural interpretation in any no-arbitrage model.

Empirical studies analyzing the evolution of exchange rates in emerging countries have been relatively limited. The paper of Caporale et al. (2016) is among the few that study the effects of exchange rates on the emerging markets. The authors used a VAR-GARCH $(1,1)$ model to analyze mean and volatility spillovers between macro news (in the form of newspaper headlines) and the exchange rates of the currencies of a group of emerging countries against the US dollar and the euro. They find dynamic linkages between the first moments compared to the second moments, causality-in-variance being found in a number of cases. The conditional correlations also provide evidence of co-movement. Further, Caporale et al. (2014), studied the linkage between stock market prices and exchange rates in advanced economies. They found that the dependence between the two variables has increased during the recent crisis, which implies limited opportunities for investors to diversify their assets during this period. Finally, the recent global financial crisis appears to have had a significant impact. Moreover, some single-country studies have been made such as Sifunjo (2011) to examine chaos and nonlinear dynamic approaches for predicting exchange rates in Kenya.

Given that the difficulty in predicting the logarithm of exchange rates has been a longstanding problem in international economics, this paper, following on from Lustig et al. (2011) and Irigoyen and Aguirre (2014), tries to predict exchange rates in the context of a two-step error correction model. While previous papers have included only the variables that are significant, this paper will give importance to the variables that might not be significant but have predictive power (Lo et al., 2014).

First, a cointegration equation is estimated for explaining the exchange rate level as a function of global and domestic financial factors. Second, to model expected 
returns, an error-correction (predictive) equation is estimated, where the change in the exchange rate is regressed on the lagged residual from the first step plus additional financial variables, also lagged and in differences. The model in this article uses other market variables to properly price exchange rates and predict currency returns. The main factor variable is constructed from the exchange rates following Engel et al. (2010). The dataset consists of a time series of five main Latin American countries from December 2001 until February 2016.

The choice of the variables to be included in the analysis is very crucial to have a good model. A spectrum of feature selection approaches exists. The so-called Lasso was first introduced by Tibshirani (1995) in order to improve the prediction accuracy and interpretability of regression models by altering the model fitting process to select only a subset of the provided covariates for use in the final model rather than using all of them. Before the Lasso approach, there were two widely used methods. The first one was the stepwise selection that was used for choosing which covariates to include, but it only improves prediction accuracy in certain cases, such as when only a few covariates have a strong relationship with the outcome. The second method was ridge regression, which improves prediction error by shrinking large regression coefficients in order to reduce over fitting, but it does not perform covariate selection. The benefit of Lasso is that it achieves both, variable selection and shrinkage, by forcing the sum of the absolute value of the regression coefficients to be less than a fixed value, thereby forcing certain coefficients to be set to zero and, effectively choosing a simpler model that does not include those coefficients. For the purpose of this article, the elastic net that extends the Lasso method for variable selection was used, which was introduced by Zou and Hastie (2005). They addressed several shortcomings of Lasso, claiming that when $p>n$ (the number of covariates is greater than the sample size) Lasso can select only $n$ covariates (even when more are associated with the outcome) and it tends to select only one covariate from any set of highly correlated covariates. Additionally, even when $n>p$, the covariates are strongly correlated, ridge regression tends to perform better. In other words, this method works by just adding another penalty to the main Lasso.

This paper provides additional evidence that the Global Exchange Rate Factor offers information about exchange rates' own movement. In addition, it shows that commodity prices and the equity market are important variables when it comes to explaining the exchange rates, where higher commodity prices lead to stronger exchange rates through an improvement in the terms-of-trade and higher stock prices signal higher expected economic growth. Furthermore, for Brazil, Peru and Mexico, measures of domestic risk premium were shown to be significant, and high levels of risk premia being associated with lower valuations and higher expected returns. Moreover, the findings for carry and slope variables are consistent with the existing literature, where higher carry leads to home currency appreciation in the next period due to its higher yield and a higher slope leads to home currency appreciation by signaling monetary policy tightening in the near term. This paper provides evidence that a higher risk aversion level, measured by the VIX index, leads to home currency appreciation in the next period by lowering the exchange rate level today 
and increasing its expected return. The Global Financial Crisis (2008) was included in the analysis and it was shown that the crisis had an effect on the exchange rate returns for the Latin American countries. Furthermore, impulse response function (IRF) and the backtest were performed.

The remainder of the paper is structured as follows. Section two describes our empirical model. Section three presents the data based on the methodology used for variable selection. The empirical results are provided in Section four. Section five provides the results of the backtesting. Lastly, Section six will conclude.

\section{Empirical Model}

\subsection{Introducing the Global Factor}

Engel et al. (2010) find evidence that exchange rates themselves offer information about common trends that are difficult to extract from observable fundamentals. Following their finding, the global variable is estimated following a nonparametric estimation using cross-sectional averaging methods more specifically principal component analysis (PCA). The key result in this method is that the principal component estimator of the space spanned by the factors is consistent and moreover, if $n$ is sufficiently large, then the factors are estimated precisely enough to be treated as data in subsequent regressions (Stock and Watson, 2011).

The idea behind a factor model is that a few factors, $f_{t}$, drive the comovement of a high-dimensional vector of time-series variables, $X_{t}$, which is also affected by a vector of mean-zero idiosyncratic disturbances, $e_{t}$ (Stock and Watson, 2011).

$$
\begin{gathered}
X_{t}=\lambda(L) f_{t}+e_{t} \\
f_{t}=\Psi(L) f_{t-1}+\eta_{t}
\end{gathered}
$$

where $L$ is the lag operator and $\lambda(L) f_{t}$ is the factor loadings matrix. The idiosyncratic disturbances are assumed to be uncorrelated with the factor innovations and mutually uncorrelated at all leads and lags.

Let $p$ be the degree of the lag polynomial matix $\lambda(L)$, let $F_{t}=\left(f_{t}^{\prime}, f_{t-1}^{\prime}, \ldots, f_{t-p}^{\prime}\right)^{\prime}$ denote an $r \times 1$, and let $\Lambda=\left(\lambda_{0}, \lambda_{1}, \ldots, \lambda_{p}\right)$, where $\lambda_{i}$ is the $n \times q$ matrix of coefficients on the $i^{\text {th }}$ lag in $\lambda(L)$. Similarly, let $\Phi(L)$ be the matrix consisting of 1's, 0's, and the elements of $\eta(L)$ such that the vector autoregression in (2) is rewritten in terms of $F_{t}$. Equation (1) and (2) can be rewritten,

$$
\begin{gathered}
X_{t}=\Lambda(L) F_{t}+e_{t} \\
\Phi(L) F_{t}=G \eta_{t}
\end{gathered}
$$

where $G$ is a matrix of 1's and 0's chosen so that Equation (4) and (2) are equivalent. But when cross-sectional averaging estimators is used, there is no need to use a parametric model for the factors $F_{t}$ as in Equation (4) neither for the idiosyncratic dynamics. Instead $F_{t}$ is treated as a $r$-dimensional parameter to be estimated using a $n$-dimensional data vector $X_{t}$. The first assumption made about the factor 
structure is that factors should affect most or all the series and that the factor loadings should be heterogenous. Moreover, the idiosyncratic disturbances should have limited correlation across series.

Consider the estimator of $F_{t}$ constructed as the weighted average of the $X_{t}$ using a nonrandom $n \times r$ matrix of weights $W$, where $W$ is normalized so that $W^{\prime} W / n=I_{r}$ :

$$
\hat{F}_{t}\left(n^{-1} W\right)=n^{-1} W^{\prime} X_{t}
$$

The principal components estimator of $F_{t}$ is the weighted averaging estimator in Equation (5), with $W=\hat{\Lambda}$, where $\hat{\Lambda}$ is the matrix of eigenvectors of the sample variance matrix $X_{t}$. The principal components estimator can be derived as the solution to the least squares problem, where the least squares estimator of $F_{t}$ is $\hat{F}_{t}=\hat{F}_{t}\left(n^{-1} \hat{\Lambda}\right)=n^{-1} \hat{\Lambda}^{\prime} X_{t}$, which are the scaled first $r$ principal components of $X_{t}^{1}$.

The first three principal components explain $86 \%$ of the total variability across the 25 exchange rates (visually presented on page 19 in Appendix), the first component accounts for $56 \%$, the second $16 \%$ and the third $14 \%$. The first principal component can be interpreted as a dollar factor that has a correlation coefficient with the DXY index ${ }^{2}$ of 0.9 , and the second principal component can be interpreted as a carry factor that has a correlation coefficient of 0.68 with Deutsche Bank's G10 FX Carry Index ${ }^{3}$, as shown in Figure 1. The third principal component has a correlation coefficient of 0.4 with JPMorgan's Global FX Volatility Index and can be interpreted as a volatility factor. Factor loadings are provided in Table 3 and evidence that the three factors are uncorrelated are provided in Table 4 on page 20 .

\subsection{Model selection}

The methodology used in this paper is a two-step-error correction model, where the first step consists in estimating a cointegration equation for the nominal exchange rate, where the exchange rate logarithmic level is explained as a function of global and domestic financial factors. In the second step, an error-correction equation is estimated, where the change in exchange rate is regressed on the lagged residual from the first step plus additional variables lagged and in differences.

\subsubsection{The cointegrating equation}

The cointegrating equation, which uncovers a long-run relationship between exchange rates and other variables, is estimated by the following equation:

$$
s_{i, t}=\delta_{i} F_{i, t}+X_{i, t}^{\top} \beta_{i}+\varepsilon_{i, t}
$$

\footnotetext{
${ }^{1}$ Data have been transformed to eliminate unit roots.

${ }^{2}$ The US Dollar Index (USDX, DXY) is an index (or measure) of the value of the United States dollar relative to a basket of foreign currencies (Euro (EUR), Japanese yen (JPY), Pound sterling (GBP), Canadian dollar (CAD), Swedish krona (SEK), Swiss franc (CHF)) often referred to as basket of US trade partners' currencies.

${ }^{3}$ Their strategy is to use the three-month interest rate to rank G10 currencies each quarter. They then buy the top-three yielding currencies and sell the bottom-three currencies. In this way, they are regularly invested in the three largest carry trades in the G10 world.
} 


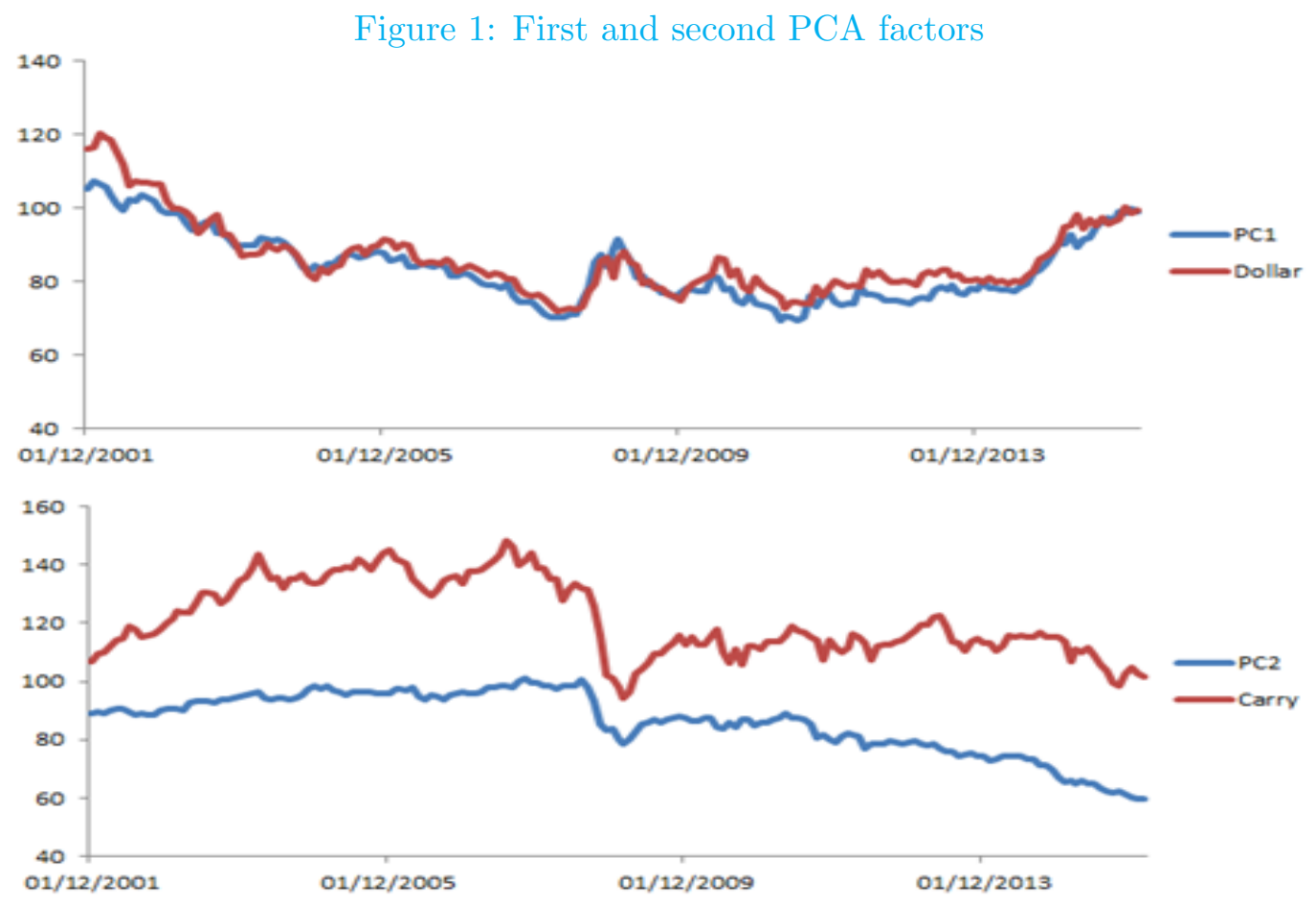

where the depended variable $s_{i, t}$ is the logarithm of exchange rate, the vector $X_{i, t}$ includes all the observable variables that were found to have an explanatory power, $F_{i, t}$ is the global variable, and $\varepsilon_{i, t}$ represents the error term.

The first-step equation was estimated by the dynamic ordinary least squares (DOLS). But since it is estimated in levels and the variables are non-stationary ${ }^{4}$, it might be the case of having spurious regression. In order to address this issue, it needs to be checked whether the variables are cointegrated; that is, if a linear combination of the variables is stationary, then the equation can be estimated in levels and the regression estimates will be valid. To test the cointegration among the variables a two-step Engle-Granger cointegration procedure was performed.

\subsubsection{The error-correction model}

It consists in estimating the following equation:

$$
d s_{i, t}=c+\theta_{i} \varepsilon_{i, t-1}+Z_{i, t-1}^{\top} \gamma_{i}+u_{i, t}
$$

where the dependent variable is the exchange rate changes for every country or the currency returns; $\varepsilon_{i, t-1}$, is the lagged residuals from the first step regression and

\footnotetext{
${ }^{4}$ The Augmented Dickey-Fuller (ADF) test provide $p$-values bigger than 0.05 , which means that we fail to reject the null hypothesis of non-stationarity. But, the $p$-values of the ADF test after differenciating the variables are all smaller than 0.05 , so we reject the null hypothesis of nonstationarity. Therefore, they are I(1).
} 
$Z$ is the set of additional explanatory variables and $c$ is a constant. The lagged residuals are the most important feature, it assumes exchange rate deviations from their fundamental value are expected to mean revert fast enough. Having said this, we are expecting to have a negative and significant coefficient. The Ordinary Least Squared methodology is used to estimate the second step.

\subsection{Variable selection}

The task of determining which predictors are associated with a given response is not a simple task. When selecting the variables, one generally looks at the individual $p$-values, but this procedure can be misleading. For instance, if the variables are highly correlated, the $p$-values will also be high, driving the researcher to a false conclusion. On the other hand, irrelevant variables may be included in the model that are not associated with the response, adding an unnecessary complexity and interpretability to the model. Also, if the number of observations is not much larger than the number of variables then there can be a lot of variability, resulting in overfitting.

There do exist some approaches for automatically performing variable selection such as stepwise methods. The problem with these methods is that they use a restricted search through the space of potential models and use a dubious hypothesis testing based on method for choosing between models instead of doing a wider search and compare models in a preferable manner. Another method used for variable selection is the Bayesian model averaging (BMA). This approach combines forecasts to extract information from different possible relationships between the predicted variable and the predictor variables. A problematic aspect of BMA, is its lack of interpretability. Because BMA includes many models, it is difficult to assess the importance of covariates in the overall prediction. For this paper, predictability and interpretability are crucial.

At this stage, this paper goes further than the existing literature on the exchange rates by using a specific methodology for variable selection, called elastic net. The reason after this choice is that elastic-net method is a combination of lasso and ridge regression, so it deals well with multicollinearity and displays the ideal properties to minimize the numerical instability that may occur due to overfitting. Most importantly, the final model involves only a subset of the predictors, which improves model interpretability, which is the important for the purpose of this paper.

Consider a sample consisting of $n$ cases, each of which consists of the $p$ covariates and a single outcome. Let $Y$ be the outcome and $X$ be the covariate matrix, so that $X_{i j}=\left(x_{i}\right)_{j}$ and $x_{i}^{T}$ is the $i^{\text {th }}$ row of $X$, then both lasso and ridge regression can be interpreted as minimizing the same objective function:

$$
\min _{\beta_{0}, \beta}\left\{\frac{1}{n}\left\|Y-\beta_{0}-X \beta\right\|_{2}^{2}\right\}
$$

but with respect to different constraints:

- $\|\beta\|_{1} \leq \tau$ for the lasso approach; 
Figure 2: Lasso vs ridge regression

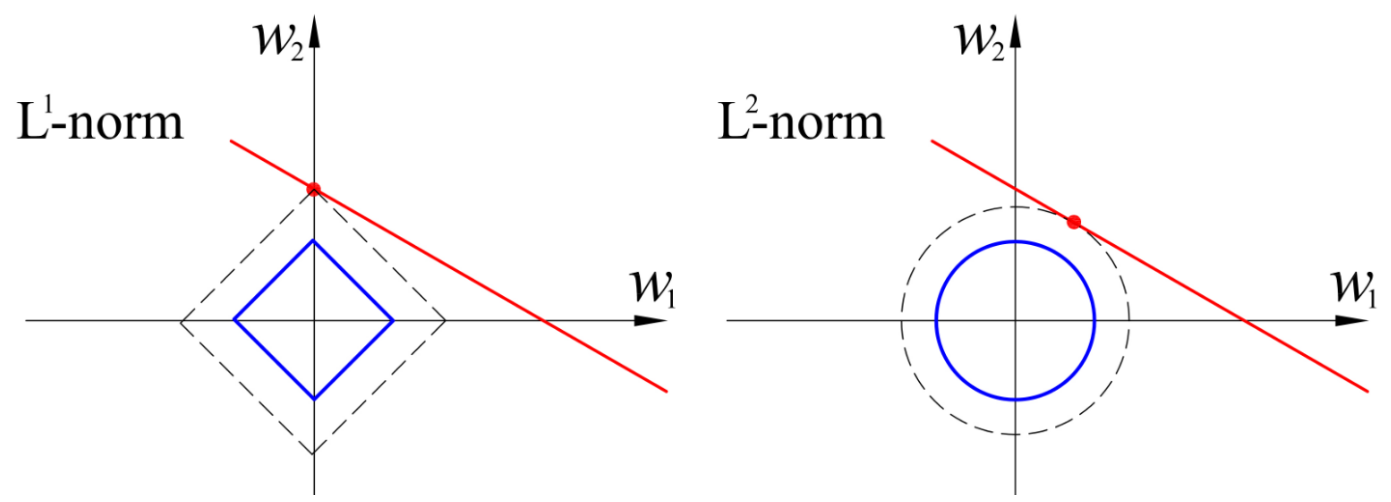

Source: Wikipedia.

- $\|\beta\|_{2}^{2} \leq \tau$ for the ridge approach.

where $\tau$ is the prespecified free parameter that determines the amount of regularization and $\|\beta\|_{p}=\left(\sum_{t=1}^{n}\left|\beta_{i}\right|^{p}\right)^{1 / p}$ is the standard $l^{p}$ norm (Zou and Hastie, 2005). From Figure 2, you can see that the constraint region defined by the $\ell^{1}$ norm is a square rotated so that its corners lie on the axes, while the region defined by the $\ell^{2}$ norm is a circle (in general an $n$-sphere) which is rotationally invariant and, therefore has no corners. As seen in the figure, a convex object that lies tangent to the boundary, such as the line shown, is likely to encounter a corner (or in higher dimensions an edge or higher-dimensional equivalent) or a hypercube, for which some components of $\beta$ are identically zero, while in the case of an $n$-sphere, the points on the boundary for which some of the components of $\beta$ are zero are not distinguished from the others and the convex object is no more likely to contact a point at which some components of $\beta$ are zero than one for which none of them are.

On the other hand, the elastic-net method uses both penalties in order to make the shrinkage and the variable selection. The regularization path is computed for the lasso or elastic-net penalty at a grid of values for the regularization parameter lambda. The algorithm is extremely fast, and can exploit sparsity in the input matrix $x$. The following is the extended elastic-net lasso that adds an additional $\ell^{2}$ penalty term (Zou and Hastie, 2005):

$$
\min _{\beta_{0}, \beta}\left\{\|Y-X \beta\|_{2}^{2}+\lambda_{1}\|\beta\|_{1}+\lambda_{2}\|\beta\|_{2}^{2}\right\}
$$

Equation (9) can be written in a different way

$$
\min _{\beta_{0}, \beta} \frac{1}{n} \sum_{t=1}^{n} \omega_{i} \mathcal{L}\left(y_{t}, \beta_{0}+x_{t}^{\top} \beta\right)+\frac{\lambda}{2}\left[(1-\alpha)\|\beta\|_{2}^{2}\right]+\alpha\|\beta\|_{1}
$$

where the tuning parameter $\lambda$ controls the overall strength of the penalty, automatically selecting the variables that have an impact on the dependent variable. Here 
$\mathcal{L}\left(y_{t}, \cdot\right)$ is the negative log-likelihood contribution for observation $t$. The elastic-net penalty is controlled by $\alpha$, and bridges the gap between lasso $(\alpha=1)$ and ridge $(\alpha$ $=0)$. This implies that the elastic-net approach includes both the ridge and lasso methods, where the $l_{1}$ part of the penalty generates a sparse model and the quadratic part of the penalty removes the limitation on the number of selected variables and stabilizes the $l_{1}$ regularization path. To estimate it, the $\mathrm{R}$ package glmnet was used. Hastie (2013) clearly established the benefits of using glmnet instead of the lars procedure such as: speed; ability to handle large variables; variety of models.

\section{Data and summary statistics}

Having data on as many countries as possible would have been very desirable but the binding constraint is the availability of comparable data among countries. Having said this, the data used in the analysis consists of time series of main frequently traded Latin America currencies: Brazilian Real (BRL), Colombian Peso (COL), Chilean Peso (CLN), Mexican Peso (MXN) and Peruvian Sol (PEN). ${ }^{5}$ Data were collected at a monthly frequency from Bloomberg. The sample begins in December 2001 and ends in February 2016. It represents 171 months in total and includes the 2008 global financial . Exchange rates are the end-of-month values for the US Dollar versus the currencies of five main Latin American countries. The analysis is done on a country by country basis. Initially, the analysis had a large number of variables without making the distinction for every country and then the methodology explained in Session 3 was implemented in order to select the best subset of variables for every currency. The log of the nominal exchange rate levels was taken before estimation. Based on this, Table 5 on page 21 provides the variables that were chosen to be used for the two-step regressions. The Principal Component Analysis in Section 2.1, was used employing monthly observations of the 25 most actively traded global exchange rates according to the 2013 Triennial Central Bank Survey from the Bank for International Settlements (BIS).

\subsection{The cointegrating equation}

Based on the variable selection methodology, the Global Exchange Rate Factor was selected to be included in the regression for every country; this variable captures the idea that exchange rates themselves offer information about their own movement. Secondly, commodity prices were included such as the CRB index for BRL, Oil prices for MXN and COP, Copper prices for CLP and, for PEN, Oil, Copper and Gold prices were selected. The intuition behind this is that higher commodity prices are expected to lead to stronger exchange rates through an improvement in the

\footnotetext{
${ }^{5}$ Based on the Triennial Central Bank Survey of foreign exchange and OTC derivatives markets in 2016, MXN was ranked 10th, BRL was ranked $18^{t h}$, CLP was ranked $30^{t h}$, COP and PEN $32^{\text {nd }}$, $35^{\text {th }}$, respectively.
} 
terms-of-trade. Moreover, a variable measuring the equity market for each country was selected, behind the choice there is an economic intuition that claims that higher stock prices signal higher expected economic growth. Furthermore, for Brazil and Peru, a measure of domestic risk premium-five year (5y) Credit Default Swap (CDS) spreads, were included in the regression, while for Mexico, one-month (1m) FX option-implied volatility was included. High levels of risk premia are usually associated with lower valuations and higher expected returns. In the end, the S\&P 500, Eurostoxx and Chiniese Equity indices were included in the analysis, capturing the trade relationship that the Latin American countries have with the United States, Europe and China.

\subsection{The error correction equation}

After the residuals of the first step, carry is the second variable included in the second step of the regression. Carry is the interest rate level differential between the home country and the US as a measure of carry, using three-month $(3 \mathrm{~m})$ implied yields. The intuition behind the use of this variable is that higher carry is expected to lead to home currency appreciation in the next period due to its higher yield. Secondly, interest rate slope differential using one month-one year (1m1y) slopes was used, as it contains relevant information about the future of monetary policy. A higher slope is expected to lead to home currency appreciation by signaling monetary policy tightening in the near term. Moreover, the so called VIX index is added in the analysis as a global risk aversion indicator. Intuitively, a higher risk aversion level may lead to home currency appreciation in the next period by lowering the exchange rate level today and increasing its expected returns. Of course, this result depends on the persistence of the process driving the VIX index. Since the recent global financial crisis is within the time horizon of this study, a dummy variable was included to capture the effect that the 2008 financial crisis has on the exchange rate returns for the five main Latin American countries ${ }^{6}$.

Some basic features of data to help guide our empirical design are provided in Tables 6 and 7 on pages 22 and 24. Means and sample ranges of the variables used are reported for the first and the second steps, respectively. There is no significant difference in mean returns. Furthermore, plots of the Henry line versus the data for each currency are provided in Figure 4 and 5. In all the plots there are some observations outside the line, in which case we would conclude against normality. In addition, the bottom panel of Table 6 shows the $p$-values of the Shapiro-Wilk test of normality as well as the $p$-values of the Jarque-Bera test of normality. Based on the results obtained, the normality hypothesis of the test was rejected (the $p$-values are lower than the significance level of $5 \%$ ), concluding that exchange rate changes are non-Gaussian and hence are not jointly and normally distributed.

\footnotetext{
${ }^{6}$ It takes the value of 1 for the 12 months of the 2008 and for the first two months of the 2009 .
} 


\subsection{Impulse response function (IRF)}

IRF was used to investigate the interactions between some of the variables and the Exchange Rates. In essence the impulse response function is based upon the world moving average representation of a $\operatorname{VAR}(p)$ process. The $(i, j)^{\text {th }}$ coefficient of the matrices $\Phi_{s}$ is thereby interpreted as the expected response of variable $y_{i, t+h}$ to a unit change in variable $y_{j, t}$. This effect can be cumulated through time $h=1,2, \ldots$, and hence one would obtain the cumulated impact of a unit change in variable $j$ on the variable $i$ at time $h$. Rather than these impulse response coefficients, it is often conceivable to use orthogonal impulse responses as an alternative. This is the case if the underlying shocks are less likely to occur in isolation but rather that contemporaneous correlation between the components of the error process $u_{t}$ exists; i.e., the off-diagonal elements of $\Sigma_{u}$ are non-zero. The orthogonal impulse responses are derived from the Cholesky decomposition of the error variance-covariance matrix $\Sigma_{u}=P P^{\top}$, with $P$ being lower triangular. The moving average representation can then be transformed to:

$$
y_{t}=\mu+\Psi_{0} \varepsilon_{t}+\Psi_{1} \varepsilon_{t-1}+\ldots+\Psi_{q} \varepsilon_{t-q}
$$

with $\varepsilon_{t}=P^{-1} u_{t}$ and $\Psi_{q}=\Phi_{q} P$ for $q=0,1,2, \ldots$ and $\Psi_{0}=P$ (Gentmen et al., 2008). Incidentally, because the matrix $P$ is lower triangular, it follows that only a shock in the first variable of a $\operatorname{VAR}(p)$ process exerts an influence on all the remaining ones and that the second and following variables cannot have a direct impact on $y_{1, t}$. One standard deviation shock is used on some of the significant variables (based on the results) in order to observe the impact they have on the dependet variables (exchange rates of the Latin American Countries).

\section{$4 \quad$ Results}

In order to validate the two-step modelling framework, the variables should be cointegrated. If this is not the case then we might be estimating a spurious regression, which will lead to not consistent estimates. Table 8 on page 25, provides the EngleGranger cointegration test results. The variables are not stationary in levels but stationary in first difference, so they are I(1). Moreover, the null hypothesis of not stationary is rejected for all the residuals obtained from the cointegration relationship ${ }^{7}$. This could be interpreted as evidence that the residuals are stationary and the series cointegrated, so the two-step modelling framework is valid.

\subsection{The cointegrating equation}

The results of the first-step regression are provided in Tables 9 and 10 on pages 26 and 27 respectively. A measure of domestic risk was found to be important for the Brazilian Real (BRL), Mexican Peso (MXN) and Peruvian Sol (PEN), five-year

\footnotetext{
${ }^{7}$ The critical values in Engle and Yoo (1987) are given in absolute value; the null hypothesis is rejected when the test statistic is negative and the magnitude is smaller than the table values (see Table 2 in Engle and Yoo (1987)).
} 
Credit Default Swaps (CDS) for the first two and one-month FX-implied volatility for the last one. Higher five-year Credit Default Swaps (CDS) spreads are associated with a weaker BRL and weaker PEN. Higher one-month FX-implied volatility is associated with a weaker MXN.

The R-squared is above 0.80 in all cases, with the exception of Colombia. The global exchange rate factor enters with a statistically significant effect in all cases, except for Peru. Commodity prices were found to be important for our Latin American Emerging countries. For the Mexican and Colombian Pesos, oil prices enter with a statistically significant negative coefficient. Moreover, for the Chilean Peso (CLP), copper prices have a significant negative effect. For Peru, based on the variable selection methodology, three were the commodity prices that were found to have an impact on Peruvian Sol; copper, gold and oil prices. When copper or gold was used, the residuals of the first step equation were not stationary, but this was not the case for oil prices. The price of oil has a statistically significant negative impact over the sample period.The negative coefficient is as expected; an increase in commodity prices is associated with a strong domestic exchange rate(lower USD/EMFX), while Brazil is the only country where the comodity index enters positively but it is not statistically significant.

Equity markets are important in Brazil. A stronger BOVESPA is associated with a stronger Brazilian real (the negative sign is due to the fact that the exchange rate is expressed USD/local), while a higher S\&P 500 index is associated with a weaker exchange rate due to dollar strengthening. Moreover, the Eurostoxx has a significant negative effect on the exchange rate of Brazil, while the effect of Chinese Equity is positive but not significant. Therefore, a stronger Eurostoxx strengthens the Brazilian real, while a stronger Chinese Equity market will have a greater effect on the dollar. On the contrary, a higher S\&P 500 is associated with a stronger Mexican peso; the strong links between the US and Mexican business cycles make MXN a higher-beta play of the USD. The impacts of Eurostoxx and Chinese Equity indices are not significant in Mexico, which once again corroborates the strong link between Mexico and the United States. For Colombia none of the equity markets are significant, while for Chile only the Chinese Equity index has a statistical positive effect. For Peru, both the S\&P 500 and Chinese Equity indices have negative effect, while the Eurostoxx index has a positive effect.

\subsection{The error-correction equation}

Table 11 on page 28, shows the results of the second step regression, error-correction equations. As expected, the regressions have low R-squared coefficients: the dependent variables are exchange rate returns and the independent variables all lag one period. The error-correction term enters with a statistically significant negative coefficient in all cases. This is evidence of mean reversion in deviations from fundamental values. Coefficients range from -0.099 to -0.320 and imply a half-life of one to three months.

The carry factor is statistically significant in all cases, except Colombia. In 
Brazil, Mexico and Peru the sign is negative: a higher local yield relative to the US leads to home currency appreciation. In Mexico, the carry factor enters in differences. Oddly, the sign is positive in Chile. It is negative in Colombia, but not significant at $10 \%$. The slope factor is statistically significant in Colombia, Chile and Peru, but not in Brazil and Mexico. Negative signs in Colombia and Peru imply a steepening in local yields relative to the US leads to home currency appreciation by signaling a tightening in domestic monetary policy in the following months.

The VIX index enters with a significant negative coefficient in Brazil, Mexico, Colombia, Chile, Peru. As stated before, a negative coefficient may signal that higher risk aversion levels lead to home currency appreciation in the next period by lowering the exchange rate level today and increasing its expected return. This result will depend on the persistence of the process driving the VIX index. Furthermore, the dummy variable enters with a significant positive effect in Brazil, Mexico, Colombia, Chile, while its effect in Peru is positive but not statistically significant.

\subsection{The impulse response function}

Figure 6 in Appendix A.6 shows the impulse response of the Brazilian Real (BRL) in the event there is a shock on Sovereign Credit Deafaut Swaps (CDS), the BOVESPA or the Eurostoxx. A shock on Brazilian CDS and the Eurostoxx will depreciate the Brazilian Real, while a shock on the BOVESPA will appreciate the BRL. Moreover, Figure 7 shows that when there is an Oil Prices shock the Mexican Peso (MXN) will appreciate; if the shock is on the SPX or on one-month FX-implied volatility (MXN FX) the MXN will depreciate. Figure 8 in Appendix A.6 shows the appreciation of the Colombian Peso (CLP) in the case of a shock on the Oil Prices; while the Chilean Peso (CLP) will appreciate, if there is a shock on Copper Prices and depreciate in the case of a shock on Chinese Equity (see Figure 9 on page 31). The depreciation of the Peruvian Sol (PEN) when there is a shock to the Eurostoxx or S\&P 500 and it appreciation if there is a shock on the Oil Prices are shown in Figure 10 in Appendix A.6. The effect on PEN of a shock on Peruvian CDS, changes over the time horizon.

\section{$5 \quad$ Backtesting}

Backtesting was conducted to evaluate the model. The model is estimated at every month-end. For the in-sample estimation, five years-December 2001 to December 2005 - were used and the remaining observations were used for out-of-sample forecasting. Recursive estimations were used; each following month, new observations were added to the dataset, the model was re-estimated and new forecasts werecalculated.

The results were compared with the momentum strategy, for which one goes long if the signal is bigger than $1 \%$, short if the signal is smaller thant $1 \%$, otherwise neutral. The first panel of Table 1 shows the model results of the backtesting exercise and the last panel provides the momentum strategy results. Sharpe ratios are also 
shown on the table and expected returns and volatility estimates are calculated monthly and annualized.

Table 1: Backtesting results

\begin{tabular}{ccccccc}
\hline Currencies & BRL & MXN & COL & PEN & CLP & All \\
\hline Model & & & & & & \\
Returns (yearly) & $4.41 \%$ & $9.81 \%$ & $6.09 \%$ & $2.03 \%$ & $14.13 \%$ & $7.81 \%$ \\
Volatility & $16.21 \%$ & $11.05 \%$ & $14.51 \%$ & $5.52 \%$ & $11.83 \%$ & $7.85 \%$ \\
Sharpe Ratio & 0.27 & 0.89 & 0.42 & 0.37 & 1.19 & 1.00 \\
\hline \hline Momentum & & & & & & \\
Returns (yearly) & $1.12 \%$ & $4.63 \%$ & $1.75 \%$ & $2.70 \%$ & $3.10 \%$ & $4.04 \%$ \\
Volatility & $10.62 \%$ & $10.39 \%$ & $12.85 \%$ & $4.78 \%$ & $10.80 \%$ & $8.92 \%$ \\
Sharpe Ratio & 0.36 & 0.44 & 0.13 & 0.56 & 0.28 & 0.45 \\
\hline
\end{tabular}

As shown, the model performs better than the momentum strategy; moreover, the model has impressive results when an equally weighted portfolio of all the currencies is created. The results are encouraging, the model provides a Sharpe ratio of 1 and an annual return of $7.81 \%$, while a common strategy for the momentum provides a Sharpe ratio of 0.45 and an annual return of $4.04 \%$. Moreover, a simple regression of the momentum strategy over the model strategy was performed, the idea behind this regression is that a significant and positive intercept $\beta_{0}$ (also known as the alpha) implies that investors that already have the momentum strategy in their portfolio, can improve their risk adjusted performance if they add this model strategy on the fringe of their portfolio.

In other words, it shows that the strategy is independent from momentum and can add value to investors that are already invested in momentum, which, as shown in Table 2, is true for all the currency returns except for Peru, where the constant is positive but not significant.

Table 12 on page 33 provides the currency correlations. As shown the currencies are not strongly correlated with one another, suggesting that model returns are also not strongly correlated across currencies. Figure 11 in Appendix A.7 shows all the cumulative returns for all the currencies, as well as the cumulative return for the 
Exchange Rate Predictability In Emerging Markets

Table 2: Model vs momentum strategy

\begin{tabular}{lccccc}
\hline & $(\mathrm{BRL})$ & $(\mathrm{MXN})$ & $(\mathrm{COL})$ & $(\mathrm{PEN})$ & $(\mathrm{CLP})$ \\
\hline Constant & $0.03^{*}$ & $0.06^{* *}$ & $0.01^{*}$ & 0.014 & $0.10^{* * *}$ \\
& $(0.033)$ & $(0.002)$ & $(0.03)$ & $(0.0014)$ & $(0.0022)$ \\
\hline Observations & 123 & 123 & 123 & 123 & 123 \\
Adjusted $\mathrm{R}^{2}$ & 0.10 & 0.11 & 0.027 & 0.047 & 0.15 \\
\hline
\end{tabular}

Note: ${ }^{*} p<0.1 ;{ }^{* *} p<0.05 ;{ }^{* * *} p<0.01$.

common strategy, while Figure 12 shows the cumulative returns of the model for each currency and those of the momentum strategy.

\section{Conclusion}

This paper finds that exchange rates themselves offer information about common trends that are difficult to extract from observable fundamentals. This is an important finding, because it implies the need for global currency risk management. If changes in exchange rates were independent and random, then buying assets in many different currencies would offer a simple diversification mechanism of currency risk. Therefore, there is a clear need to hedge the currency exposures. A strong link between currency carry and the exchange rate return was found as well as slope factor and currency returns. Further, it documents that currency returns are positively correlated with increases in implied stock market volatility VIX. Moreover, exchange rate returns depend on the crisis. An extension of the current framework to the major Eastern European, Middle Eastern, and African (EEMEA) and Asian currencies, will be necessary to have a more complete view of exchange rate movements in emerging markets. 


\section{References}

[1] Ang, A., and Chen, J. (2013), Yield Curve Predictors of Foreign Exchange Returns, Columbia University, Working Paper.

[2] Bacchetta, P., and Van Wincoop, E. (2006), Can Information Heterogeneity Explain the Exchange Rate Determination Puzzle?, American Economic Review, 96(3), pp. 552-576.

[3] BAI, J. (2004), Estimating Cross-Section Common Stochastic Trends in Nonstationary Panel Data, Journal of Econometrics, 122(1), pp. 137-183.

[4] Banerjee, A., Marcellino, M., and Masten, I. (2014), Forecasting with factor-augmented error correction models, International Journal of Forecasting, 30(3), pp. 589-612.

[5] Benigno, G., and Benigno, P. (2008), Exchange Rate Determination Under Interest Rate Rules, Journal of International Money and Finance, 27(6), pp. 971-993.

[6] Brunnermeier, M.K., Nagel, S., and Pedersen, L.H. (2008), Carry Trades and Currency Crashes, NBER Macroeconomics Annual, 23(1), pp. 313-348.

[7] Caporale, G.M., Spagnolo, F., and Spagnolo, N. (2016), Exchange Rates and Macro News in Emerging Markets, Working Paper.

[8] Caporale, G.M., Hunter, J., and Ali, F.M. (2014), On the Linkages Between Stock Prices and Exchange Rates: Evidence from the banking crisis of 2007-2010, International Review of Financial Analysis, 33(1), pp. 87-103.

[9] Diebold, F.X., Gardeazabal, J., and Yilmaz, K. (1994), On Cointegration and Exchange Rate Dynamics, Journal of Finance, 49(2), pp. 727-735.

[10] Engel, C., Mark, N.C., and West, K.D. (2012), Factor Model Forecasts of Exchange Rates, Econometric Reviews, 34(1-2), pp. 32-55.

[11] Engel, C., Mark, N.C., West, K.D., Rogoff, K., and Rossi, B. (2007), Exchange Rate Models Are Not as Bad as You Think, NBER Macroeconomics Annual, 22(1), pp. 381-473.

[12] Engel, C., and West, K.D. (2004), Taylor Rules and the Deutschmark-Dollar Real Exchange Rate, National Bureau of Economic Research, No. w10995.

[13] Engel, C., and West, K.D. (2005), Exchange Rates and Fundamentals, Journal of Political Economy, 113(3), pp. 485-517.

[14] Engle, R.F., and Yoo, B.S. (1987), Forecasting and Testing in Co-integrated Systems, Journal of Econometrics, 35(1), pp. 143-159. 
[15] Groen, J.J. (2005), Exchange Rate Predictability and Monetary Fundamentals in a Small Multi-Country Panel, Journal of Money, Credit, and Banking, 37(3), pp. $495-516$.

[16] Groen, J.J. (2006), Fundamentals Based Exchange Rate Prediction Revisited, manuscript, Bank of England.

[17] Irigoyen, C., and Aguirre, E. (2014), Forecasting with Compass30, Bank of America Merrill Lynch, Working Paper.

[18] Jobson, J.D., and Korkie, B.M. (1981), Performance Hypothesis Testing with the Sharpe and Treynor Measures, Journal of Finance, 36(4), pp. 889-908.

[19] Lustig, H., Roussanov, N., and Verdelhan, A. (2011), Common Risk Factors in Currency Markets, Review of Financial Studies, 24(11), pp. 3731-3777.

[20] Mansoumi, E., and Bulut, L. (2013), Predictability and Specification in Models of Exchange Rate Determination, In Recent Advances and Future Directions in Causality, Prediction, and Specification Analysis, Springer New York, pp. 411-436.

[21] Mark, N.C. (1995), Exchange Rates and Fundamentals: Evidence on LongHorizon Predictability, American Economic Review, 85(1), pp. 201-218.

[22] Mark, N.C. (2001), International Macroeconomics and Finance: Theory and Empirical Methods, Blackwell.

[23] Mark, N.C. (2009), Changing Monetary Policy Rules, Learning, and Real Exchange Rate Dynamics, Journal of Money, Credit and Banking, 41(6), pp. 1047-1070.

[24] Mark, N.C., and Sul, D. (2001), Nominal Exchange Rates and Monetary Fundamentals: Evidence from a Small Post-Bretton Woods Panel, Journal of International Economics, 53(1), pp. 29-52.

[25] Meese, R.A., and Rogoff, K. (1983), Empirical Exchange Rate Models of the Seventies: Do They Fit Out of Sample?, Journal of International Economics, 14(1-2), pp. 3-24.

[26] Meese, R., and Rogoff, K. (1983), The Out-of-Sample Failure of Empirical Exchange Rate Models: Sampling Error or Misspecification?, In Exchange Rates and International Macroeconomics, University of Chicago Press, pp. 67-112.

[27] Molodtsova, T., Nikolsko-Rzhevskyy, A., and Papell, D.H. (2008), Taylor Rules with Real-Time Data: A Tale of Two Countries and One Exchange Rate, Journal of Monetary Economics, 55(1), pp. S63-S79.

[28] Rogoff, K.S., and Stavrakeva, V. (2008), The Continuing Puzzle of Short Horizon Exchange Rate Forecasting, National Bureau of Economic Research, No. w14071. 
[29] Sifunjo, E.K. (2011), Chaos and non-linear dynamical approaches to predicting exchange rates in Kenya, Unpublished PhD Thesis, School of Business, University of Nairobi.

[30] Stock, J.H., and Watson, M.W. (2006), Forecasting with Many Predictors, Handbook of Economic Forecasting, 1, pp. 515-554.

[31] Stock, J.H., and Watson, M.W. (2011), Dynamic Factor Models, Handbook on Economic Forecasting.

[32] Verdelhan, A. (2018), The Share of Systematic Variation in Bilateral Exchange Rates, Journal of Finance, forthcoming.

[33] West, K.D. (1996), Asymptotic Inference about Predictive Ability, Econometrica, 64(5), pp. 1067-1084.

[34] West, K.D. (2006), Forecast Evaluation, Handbook of Economic Forecasting, 1 , pp. 99-134.

[35] West, K.D., Edison, H.J., and Cho, D. (1993), A Utility-Based Comparison of Some Models of Exchange Rate Volatility, Journal of International Economics, 35(1-2), pp. 23-45.

[36] Zou, H., and Hastie, T. (2005), Regularization and Variable Selection Via the Elastic Net, Journal of the Royal Statistical Society: Series B, 67(2), pp. 301-320. 


\section{A Appendix}

\section{A.1 Graphical representation}

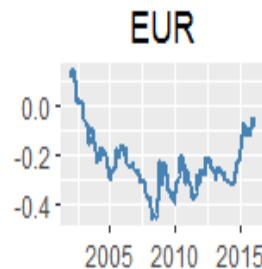

JPY

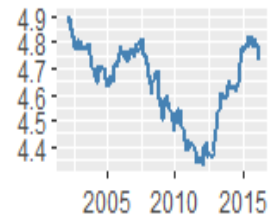

GBP

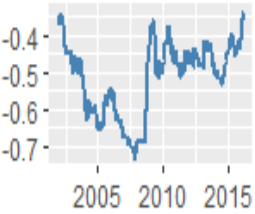

AUD

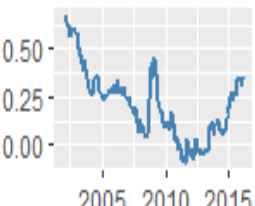

200520102015

$\mathrm{CHF}$

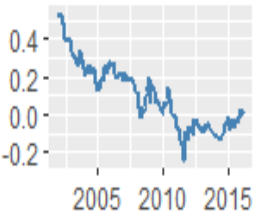

200520102015
$C A D$

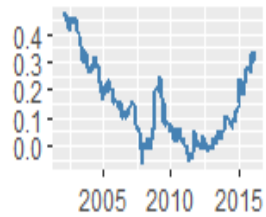

NZD

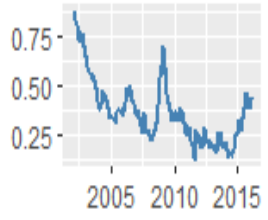

SEK

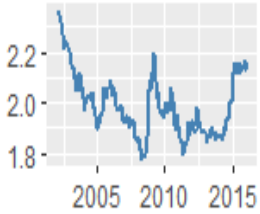

RUB

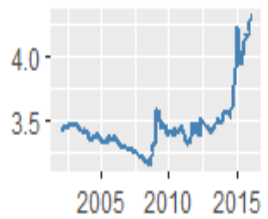

NOK

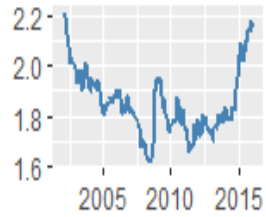

SGD

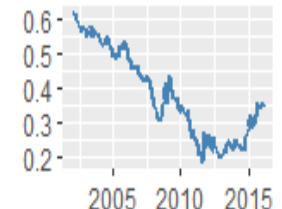

TRY

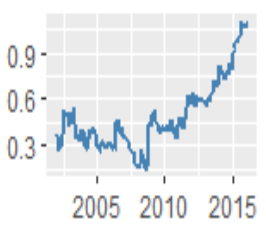

KRW

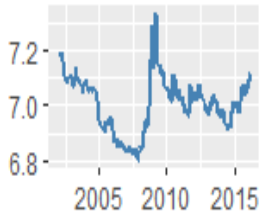

ZAR

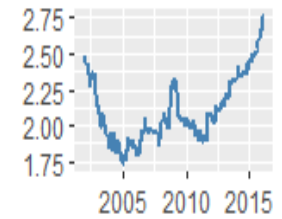

INR

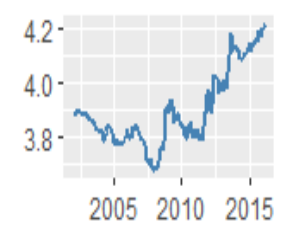

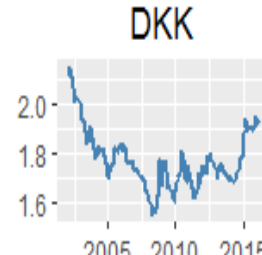

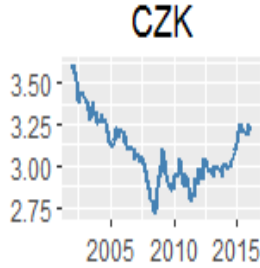

PLN
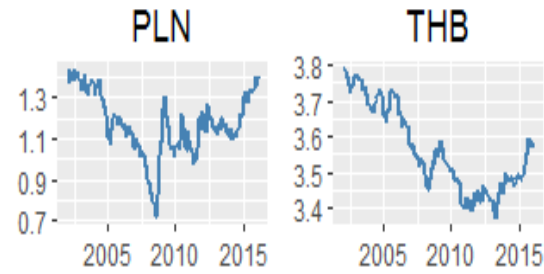

TWD
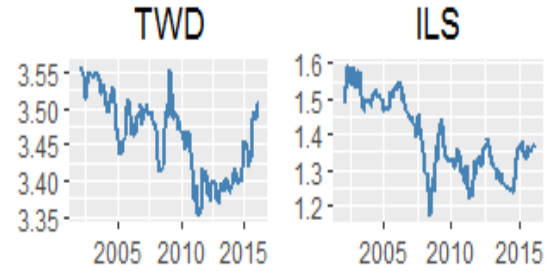

HUF

IDR
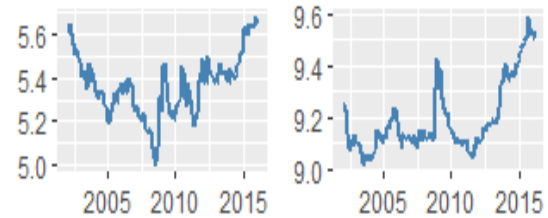

MYR

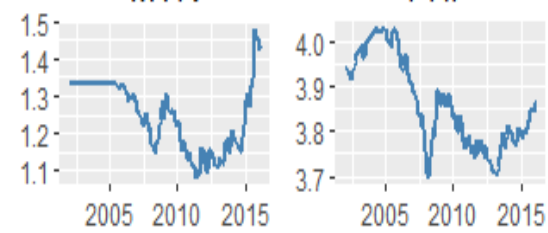

Figure 3: Exchange rate graphical representation 


\section{A.2 PCA factors}

Table 3: Loadings of factors

\begin{tabular}{lrrr}
\hline & $(1)$ & \multicolumn{1}{c}{$(2)$} & \multicolumn{1}{c}{$(3)$} \\
\hline EUR & -0.2342 & 0.2762 & 0.0557 \\
JPY & -0.0554 & 0.2116 & -0.6392 \\
GBP & -0.1872 & 0.1552 & 0.1511 \\
AUD & -0.2400 & -0.1105 & 0.0831 \\
CHF & -0.2051 & 0.2385 & -0.2459 \\
CAD & -0.1946 & -0.0991 & 0.1987 \\
NZD & -0.2231 & -0.0544 & 0.0696 \\
SEK & -0.2366 & 0.1994 & 0.0524 \\
RUB & -0.1739 & -0.0135 & 0.0983 \\
NOK & -0.2254 & 0.1319 & 0.0800 \\
SGD & -0.2390 & -0.0562 & -0.1935 \\
TRY & -0.1487 & -0.3540 & 0.2951 \\
KRW & -0.2062 & -0.1300 & -0.1306 \\
ZAR & -0.1730 & -0.1707 & 0.1330 \\
INR & -0.1730 & -0.2668 & -0.0852 \\
DKK & -0.2368 & 0.2686 & 0.0541 \\
PLN & -0.2335 & 0.1125 & 0.1721 \\
TWD & -0.1959 & -0.0820 & $-0,2612$ \\
HUF & -0.2295 & 0.1556 & 0.1558 \\
MYR & -0.1870 & -0.2609 & $-0,1339$ \\
CZK & -0.2274 & 0.2733 & 0.0702 \\
THB & -0.1824 & -0.1632 & $-0,3073$ \\
ILS & -0.1656 & 0.0141 & 0.0173 \\
IDR & -0.1634 & -0.2959 & -0.0413 \\
PHP & -0.1593 & -0.3115 & -0.1553 \\
\hline & & &
\end{tabular}

Table 4: Factor correlations

\begin{tabular}{lccc}
\hline Correlation & Factor 1 & Factor 2 & Factor 3 \\
\hline Factor 1 & 1.00 & & \\
Factor 2 & 0.00 & 1.00 & \\
Factor 3 & 0.00 & 0.00 & 1.00 \\
\hline
\end{tabular}




\section{A.3 List of variables}

Table 5: The selected variables

\begin{tabular}{lccccc}
\hline Included variables & BRL & MXN & COP & CLP & PEN \\
\hline Cointegration equation & & & & & \\
Global Factor & $\sqrt{ }$ & $\sqrt{ }$ & $\sqrt{ }$ & $\sqrt{ }$ & $\sqrt{ }$ \\
CRB Index & $\sqrt{ }$ & & & & \\
Oil prices & & $\sqrt{ }$ & $\sqrt{ }$ & & $\sqrt{ }$ \\
Copper prices & & & & $\sqrt{ }$ & $\sqrt{ }$ \\
Gold prices & & & & & $\sqrt{ }$ \\
BOVESPA Index & $\sqrt{ }$ & & & & \\
CDS & $\sqrt{ }$ & $\sqrt{ }$ & & & $\sqrt{ }$ \\
FX option volatility & $\sqrt{ }$ & $\sqrt{ }$ & $\sqrt{ }$ & $\sqrt{ }$ & \\
S\&P 500 & $\sqrt{ }$ & $\sqrt{ }$ & $\sqrt{ }$ & $\sqrt{ }$ & $\sqrt{ }$ \\
Equity China & $\sqrt{ }$ & $\sqrt{ }$ & $\sqrt{ }$ & $\sqrt{ }$ & $\sqrt{ }$ \\
Eurostoxx & & & & & \\
Error correction Equation & $\sqrt{ }$ & $\sqrt{ }$ & $\sqrt{ }$ & $\sqrt{ }$ & $\sqrt{ }$ \\
Carry differential & $\sqrt{ }$ & $\sqrt{ }$ & $\sqrt{ }$ & $\sqrt{ }$ & $\sqrt{ }$ \\
Slope differential & $\sqrt{ }$ & $\sqrt{ }$ & $\sqrt{ }$ & $\sqrt{ }$ & $\sqrt{ }$ \\
VIX & $\sqrt{ }$ & $\sqrt{ }$ & $\sqrt{ }$ & $\sqrt{ }$ & $\sqrt{ }$ \\
Crisis dummy & & & & & \\
&
\end{tabular}




\section{A.4 Additional results}

Table 6: Summary statistics for the first step

\begin{tabular}{lccccr}
\hline Statistic & $\mathrm{N}$ & Mean & St. Dev. & Min & Max \\
\hline MXN & 171 & 2.49 & 0.14 & 2.20 & 2.90 \\
BRL & 171 & 0.82 & 0.24 & 0.44 & 1.39 \\
CLP & 171 & 6.33 & 0.13 & 6.08 & 6.62 \\
COP & 171 & 7.70 & 0.17 & 7.47 & 8.10 \\
PEN & 171 & 1.12 & 0.10 & 0.94 & 1.29 \\
Global Factor & 171 & 6.95 & 0.15 & 6.76 & 7.38 \\
CRB Index & 171 & 5.61 & 0.23 & 4.98 & 6.14 \\
Oil prices & 171 & 4.14 & 0.46 & 2.97 & 4.94 \\
Copper prices & 171 & 8.52 & 0.56 & 7.27 & 9.20 \\
Gold prices & 171 & 6.69 & 0.56 & 5.62 & 7.50 \\
BOVESPA Index & 171 & 10.57 & 0.56 & 9.06 & 11.19 \\
Peru CDS & 171 & 5.44 & 0.46 & 4.61 & 6.78 \\
Brazil CDS & 171 & 5.76 & 0.61 & 4.94 & 7.79 \\
FX option volatility & 171 & 2.31 & 0.38 & 1.69 & 3.68 \\
S\&P 500 & 171 & 7.17 & 0.25 & 6.60 & 7.65 \\
Equity China & 171 & 7.69 & 0.39 & 6.97 & 8.69 \\
Eurostoxx & 171 & 8.01 & 0.19 & 7.59 & 8.41 \\
\hline Exchange Rates & Shapiro-Wilk & & Jarque-Bera & & \\
\hline MXN & 0.00 & & 0.008 & & \\
BRL & 0.00 & & 0.016 & & \\
CLP & 0.00 & & 0.002 & & \\
COP & 0.00 & & 0.004 & & \\
PEN & 0.00 & & & & \\
\hline
\end{tabular}



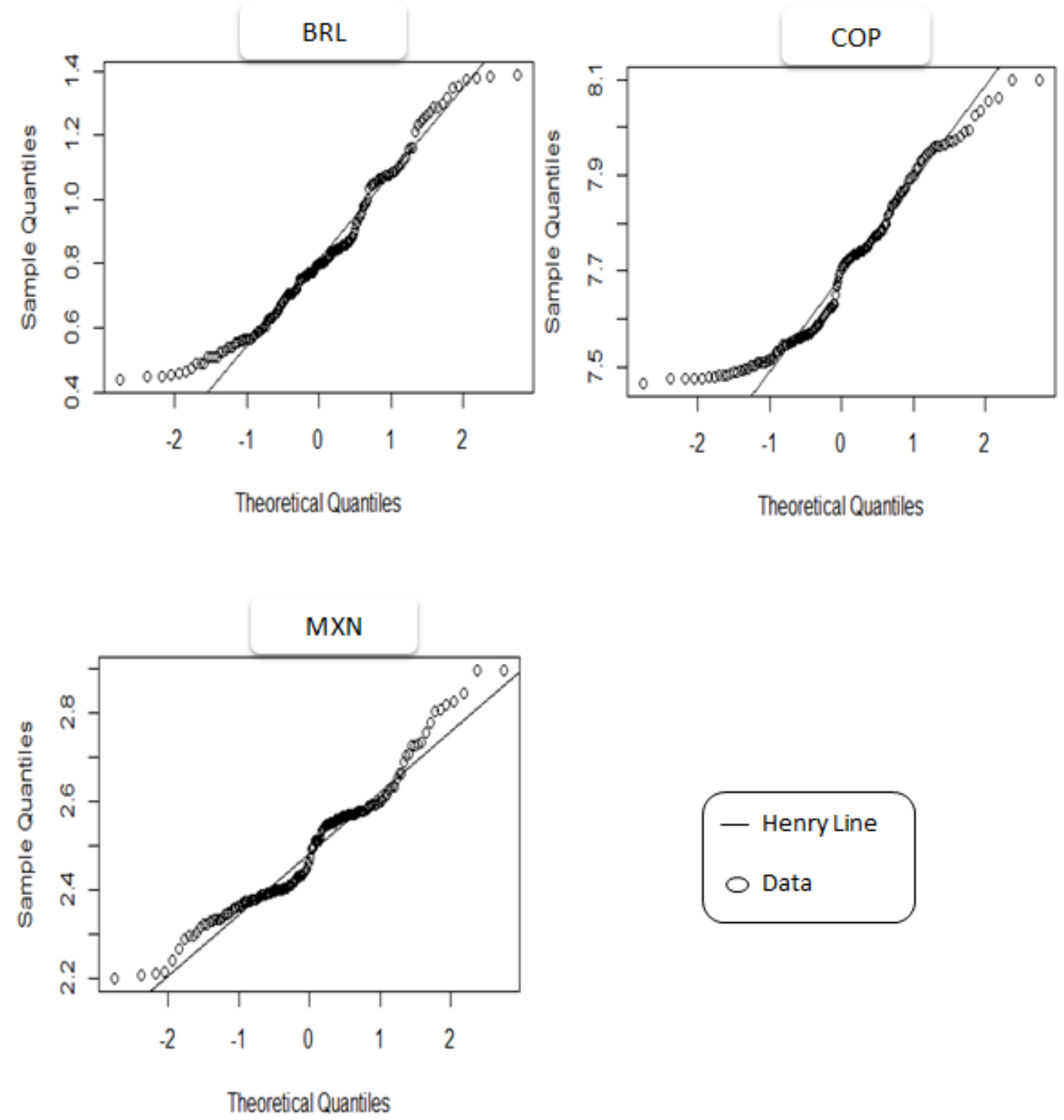

Figure 4: Henry plot 

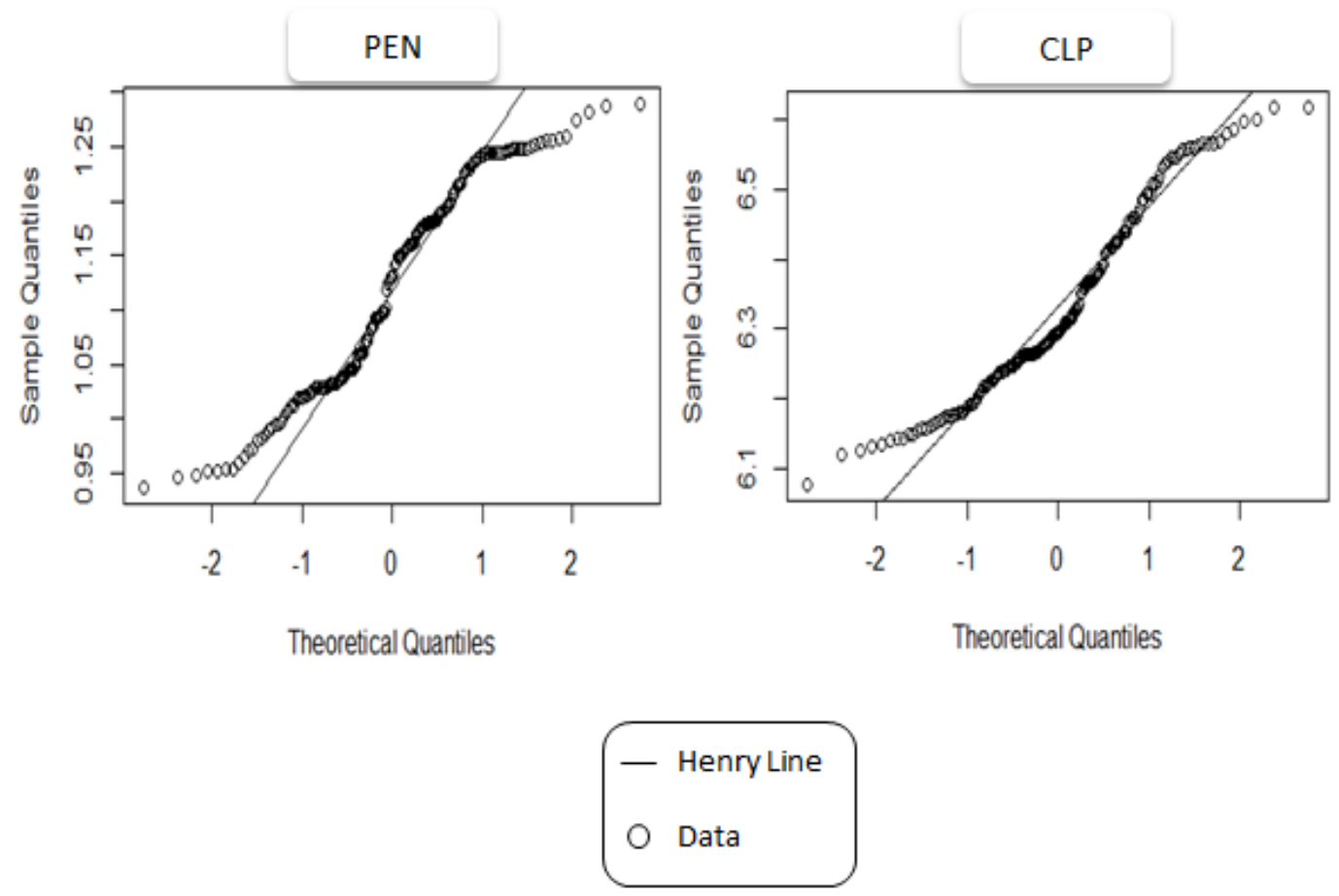

Figure 5: Henry plot

Table 7: Summary statistics for the second step

\begin{tabular}{lcrcrr}
\hline Statistic & $\mathrm{N}$ & Mean & St. Dev. & \multicolumn{1}{c}{ Min } & Max \\
\hline Carry Brazil & 171 & 11.93 & 4.51 & 5.53 & 26.14 \\
Slope Brazil & 171 & 0.02 & 1.94 & -3.47 & 10.71 \\
Carry Mexico & 171 & 4.36 & 1.80 & 1.701 & 12.70 \\
Slope Mexico & 171 & 0.11 & 0.94 & -2.04 & 4.79 \\
Carry Colombia & 171 & 4.43 & 1.81 & 0.54 & 8.94 \\
Slope Colombia & 171 & 0.94 & 2.60 & -7.34 & 13.85 \\
Carry Chile & 171 & 2.09 & 2.05 & -3.09 & 6.74 \\
Slope Chile & 171 & -0.30 & 1.07 & -3.87 & 2.16 \\
Carry Peru & 171 & 2.00 & 2.58 & -5.56 & 12.10 \\
Slope Peru & 171 & -0.14 & 1.81 & -8.31 & 6.69 \\
VIX & 171 & 20.20 & 8.45 & 10.42 & 59.89 \\
Crisis & 171 & 0.05 & 0.21 & 0.00 & 1.00 \\
\hline
\end{tabular}




\section{A.5 Estimated parameters}

Table 8: Engle Granger two-step test

\begin{tabular}{lcccc}
\hline & \multicolumn{4}{c}{ First step results } \\
\cline { 2 - 5 } & In level & & In difference \\
& Dickey Fuller & p-value & Dickey Fuller & p-value \\
\hline BRL & -0.71 & 0.96 & -4.95 & 0.01 \\
MXN & -2.40 & 0.41 & -5.82 & 0.01 \\
COP & -0.52 & 0.98 & -5.82 & 0.01 \\
CLP & -1.23 & 0.90 & -4.84 & 0.01 \\
PEN & 0.14 & 0.99 & -4.09 & 0.01 \\
Global Factor & -1.80 & 0.66 & -5.74 & 0.01 \\
CRB & -1.90 & 0.62 & -5.02 & 0.01 \\
S\&P 500 & -2.55 & 0.35 & -5.12 & 0.01 \\
BOVESPA & -1.19 & 0.91 & -5.99 & 0.01 \\
Europe & -2.60 & 0.33 & -4.59 & 0.01 \\
China & -2.97 & 0.17 & -4.34 & 0.01 \\
Brazil CDS & -1.35 & 0.85 & -6.55 & 0.01 \\
Oil & -1.08 & 0.92 & -5.72 & 0.01 \\
MXN FX & -3.38 & 0.06 & -6.11 & 0.01 \\
Copper & -1.56 & 0.76 & -5.81 & 0.01 \\
Peru CDS & -2.66 & 0.30 & -6.10 & 0.01 \\
Gold & -0.17 & 0.99 & -4.76 & 0.01 \\
\hline & & Second step results & \\
& & &
\end{tabular}

Test statistic

Residuals for Brazil $\quad-3.60$

Residuals for Mexico $\quad-3.35$

Residuals for Colombia $\quad-3.20$

Residuals for Chile $\quad-3.25$

Residuals for Peru $\quad-3.50$ 
Table 9: First step results

\begin{tabular}{|c|c|c|c|}
\hline & \multicolumn{3}{|c|}{ Dependent variable } \\
\hline & $\begin{array}{c}\text { BRL } \\
(1) \\
\end{array}$ & $\begin{array}{c}\text { MXN } \\
(2) \\
\end{array}$ & $\begin{array}{c}\text { COP } \\
(3) \\
\end{array}$ \\
\hline $\mathrm{F}$ & $\begin{array}{c}0.573^{* * *} \\
(0.109)\end{array}$ & $\begin{array}{c}0.041^{* * *} \\
(0.004)\end{array}$ & $\begin{array}{c}0.258^{* * *} \\
(0.067)\end{array}$ \\
\hline CRB Index & $\begin{array}{c}0.013 \\
(0.067)\end{array}$ & & \\
\hline Oil prices & & $\begin{array}{c}-0.121^{* * *} \\
(0.012)\end{array}$ & $\begin{array}{c}-0.304^{* * *} \\
(0.019)\end{array}$ \\
\hline S\&P 500 & $\begin{array}{c}0.374^{* * *} \\
(0.057)\end{array}$ & $\begin{array}{c}-0.122^{* *} \\
(0.051)\end{array}$ & $\begin{array}{c}0.016 \\
(0.049)\end{array}$ \\
\hline BOVESPA Index & $\begin{array}{c}-0.306^{* * *} \\
(0.066)\end{array}$ & & \\
\hline MXN_FX & & $\begin{array}{c}0.064^{* * *} \\
(0.017)\end{array}$ & \\
\hline Eurostoxx & $\begin{array}{c}-0.230^{* * *} \\
(0.057)\end{array}$ & $\begin{array}{c}0.044 \\
(0.039)\end{array}$ & $\begin{array}{c}0.021 \\
(0.043)\end{array}$ \\
\hline Equity China & $\begin{array}{c}0.041 \\
(0.039)\end{array}$ & $\begin{array}{l}-0.007 \\
(0.014)\end{array}$ & $\begin{array}{l}-0.031 \\
(0.021)\end{array}$ \\
\hline Brazil CDS & $\begin{array}{l}0.119^{* *} \\
(0.049)\end{array}$ & & \\
\hline Constant & $\begin{array}{c}-1.841^{* *} \\
(0.883)\end{array}$ & $\begin{array}{c}3.130^{* * *} \\
(0.318)\end{array}$ & $\begin{array}{c}7.122^{* * *} \\
(0.438)\end{array}$ \\
\hline Observations & 171 & 171 & 171 \\
\hline Adjusted $\mathrm{R}^{2}$ & 0.836 & 0.894 & 0.736 \\
\hline
\end{tabular}


Table 10: First step results

\begin{tabular}{lcc}
\hline & \multicolumn{2}{c}{ Dependent variable: } \\
\cline { 2 - 3 } & CLP & PEN \\
& $(1)$ & $(2)$ \\
\hline F & $0.313^{* * *}$ & $0.033^{* * *}$ \\
& $(0.039)$ & $(0.028)$ \\
Peru CDS & & $0.053^{* * *}$ \\
& & $(0.012)$
\end{tabular}

$\begin{array}{cc}\text { Copper prices } & -0.242^{* * *} \\ & (0.010)\end{array}$

Oil prices

$-0.127^{* * *}$

(0.010)

\begin{tabular}{lcc} 
S\&P 500 & $\begin{array}{c}0.041 \\
(0.029)\end{array}$ & $\begin{array}{c}-0.045^{*} \\
(0.022)\end{array}$ \\
Eurostoxx & $\begin{array}{l}-0.038 \\
(0.025)\end{array}$ & $\begin{array}{c}0.225^{* * *} \\
(0.018)\end{array}$ \\
& & $-0.040^{* * *}$ \\
Equity China & $0.056^{* * *}$ & $(0.008)$ \\
& $(0.013)$ & -0.044 \\
Constant & $5.788^{* * *}$ & $(0.233)$ \\
& $(0.256)$ & 171 \\
\hline Observations & 171 & 0.873 \\
Adjusted $\mathrm{R}^{2}$ & 0.857 & \\
\hline Note & $*$ &
\end{tabular}


Table 11: Results for the second step

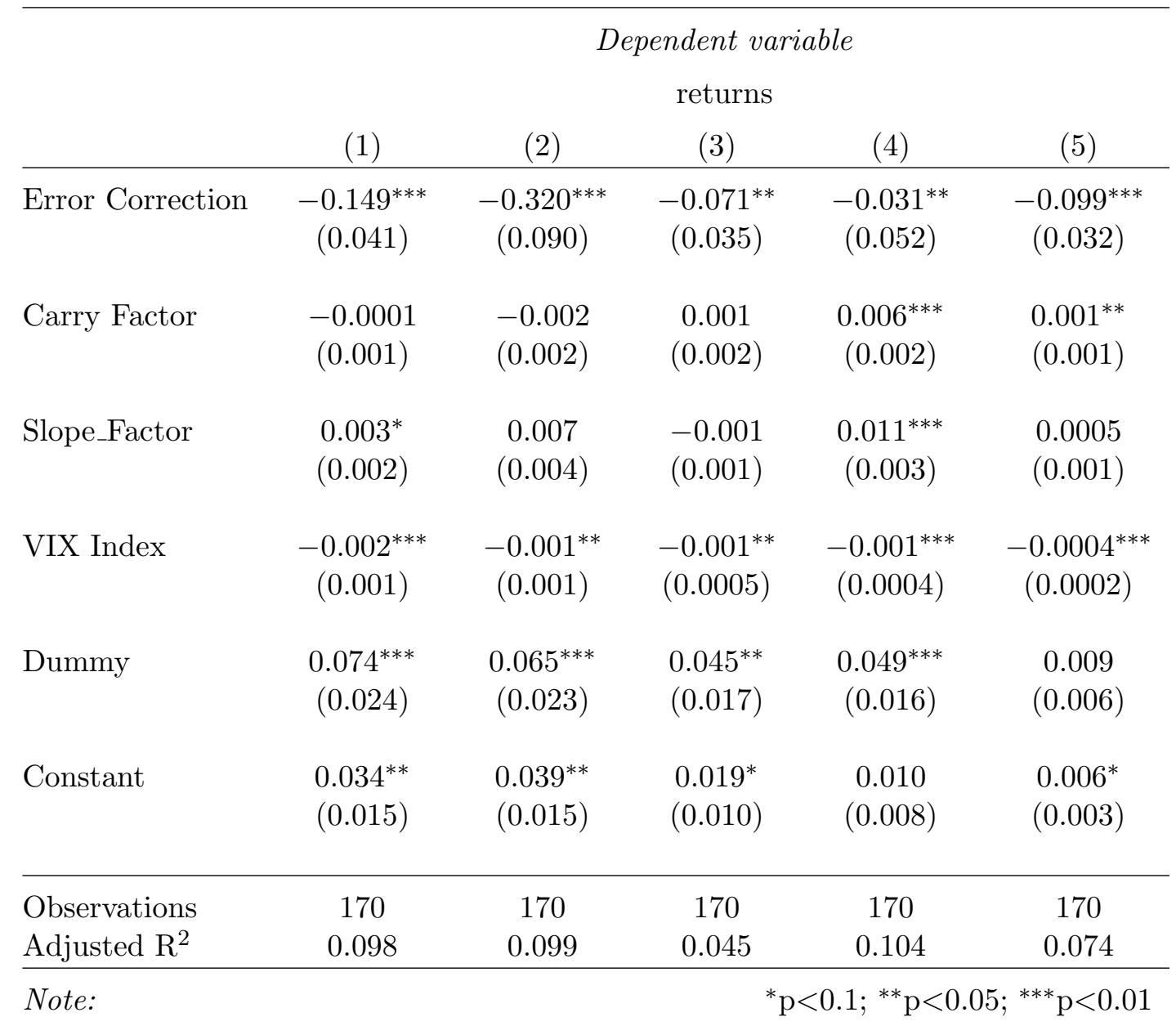




\section{A.6 Impulse response functions}

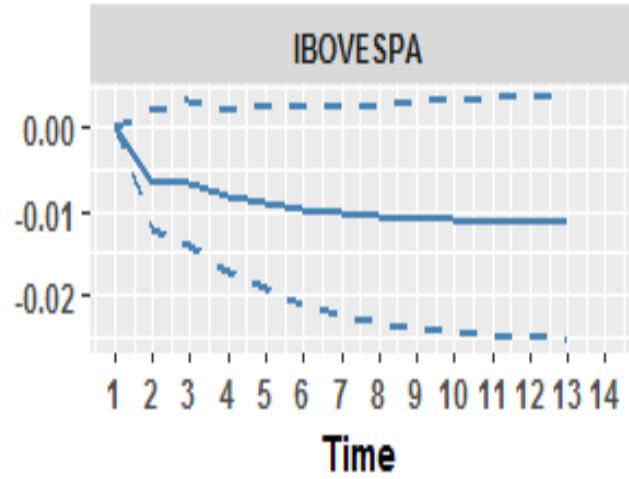

- IBOVESPA

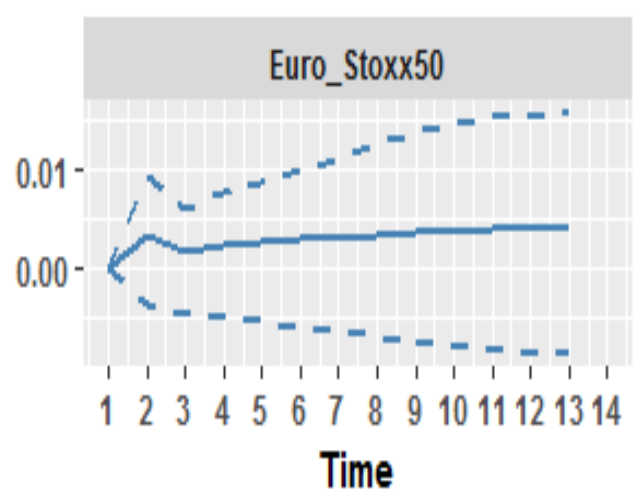

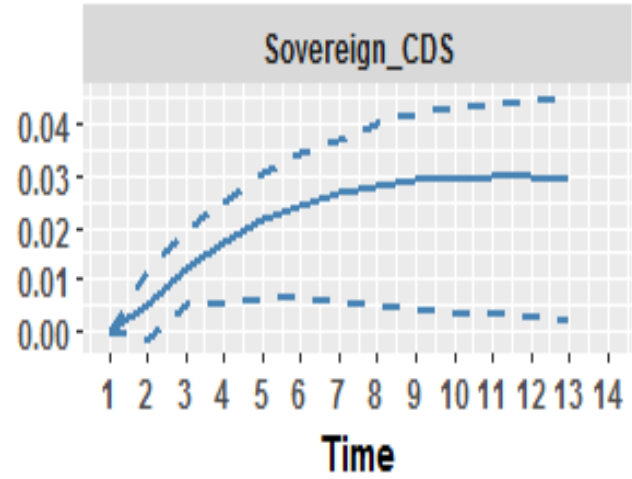

- Sovereign_CDS

\section{- Euro_Stoxx50}

Figure 6: Impulse response function for Brazil 


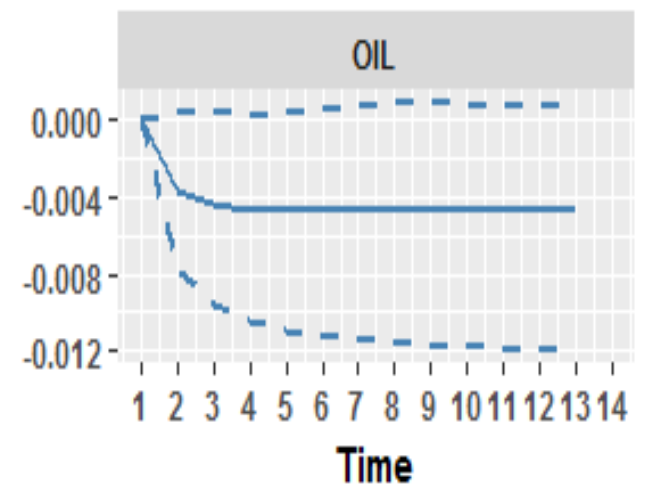

- oll

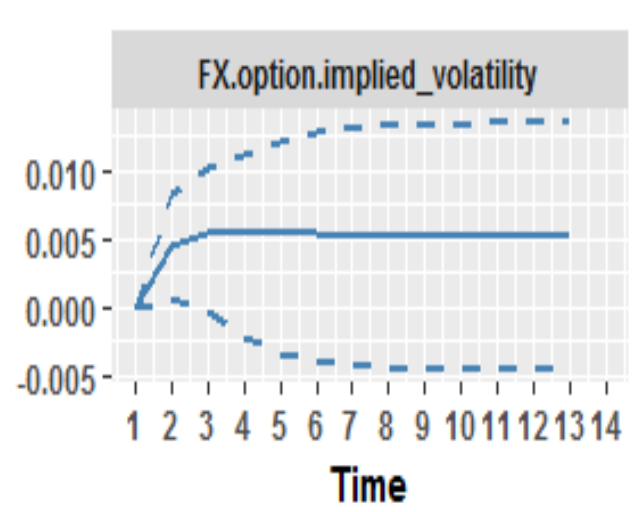

\section{- FX.option.implied_volatility}

Figure 7: Impulse response function for Mexico

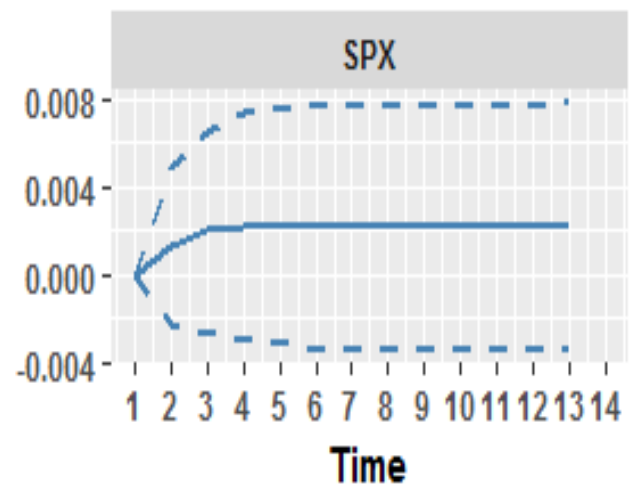

- SPX 


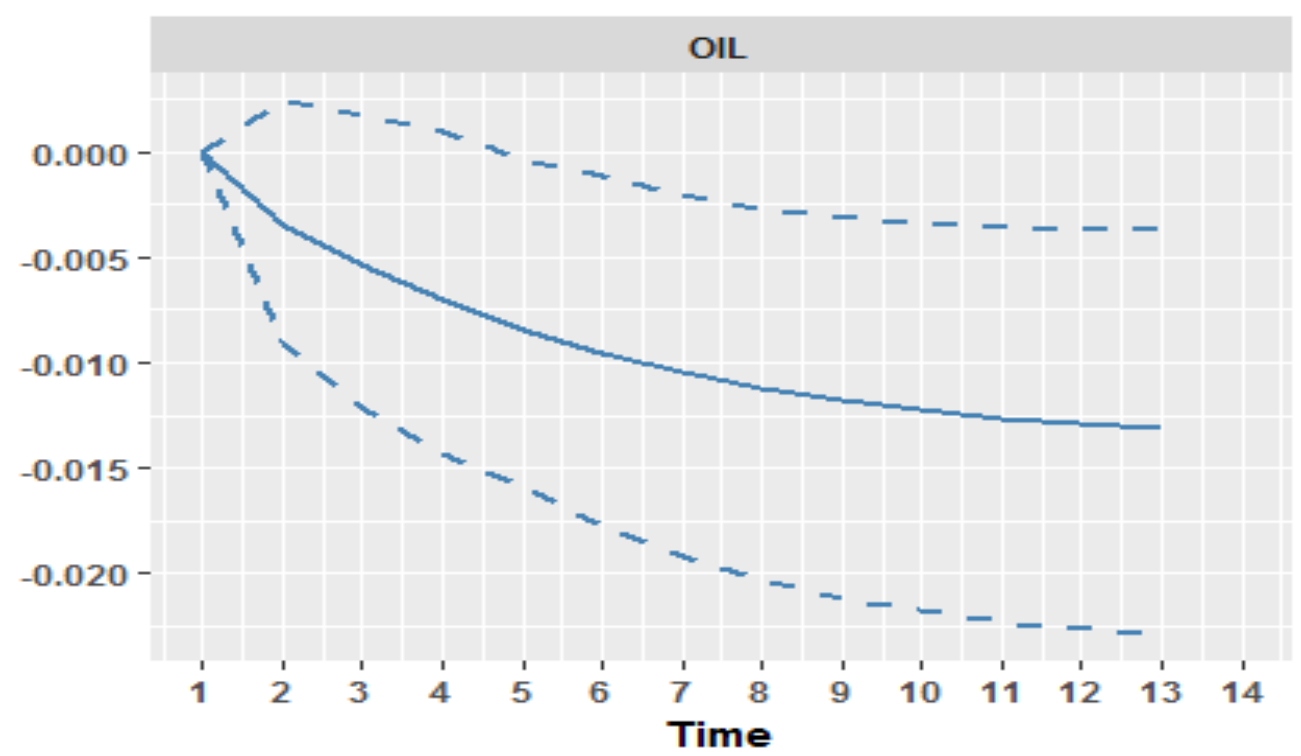

- OIL

Figure 8: Impulse response function for Colombia

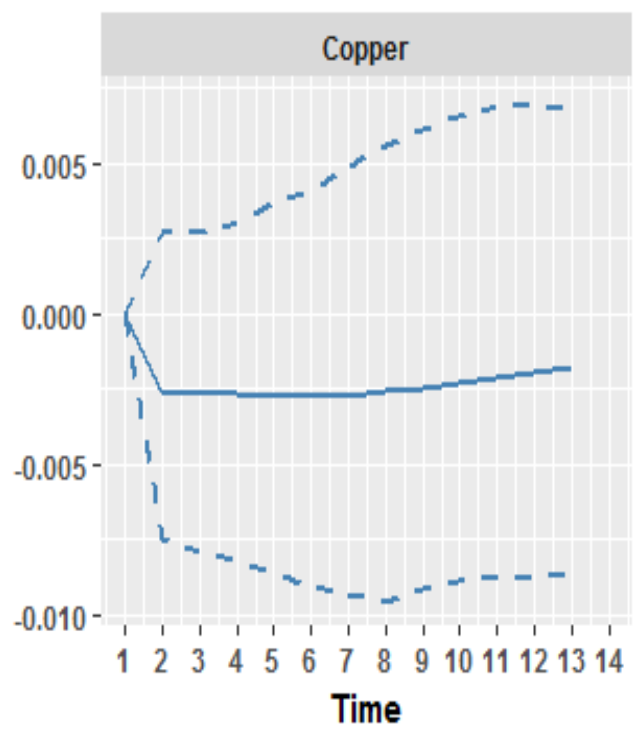

- Copper

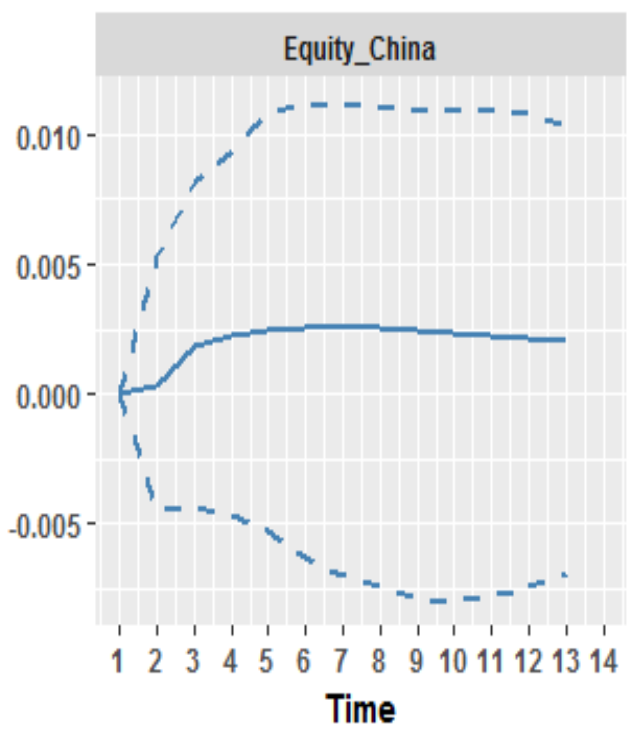

Equity_China

Figure 9: Impulse response function for Chile 


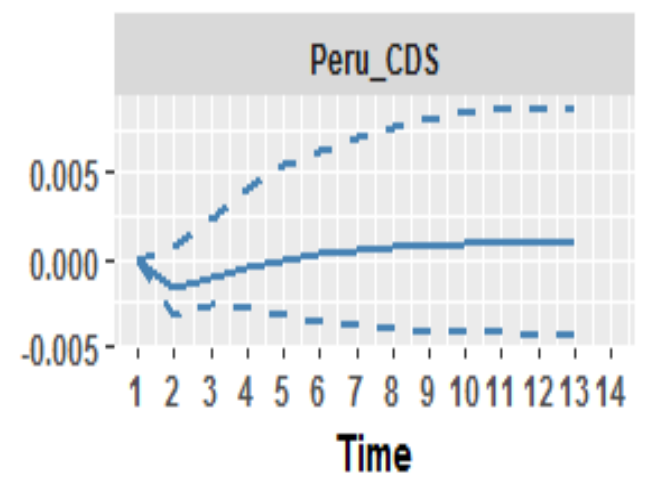

- Peru_CDS

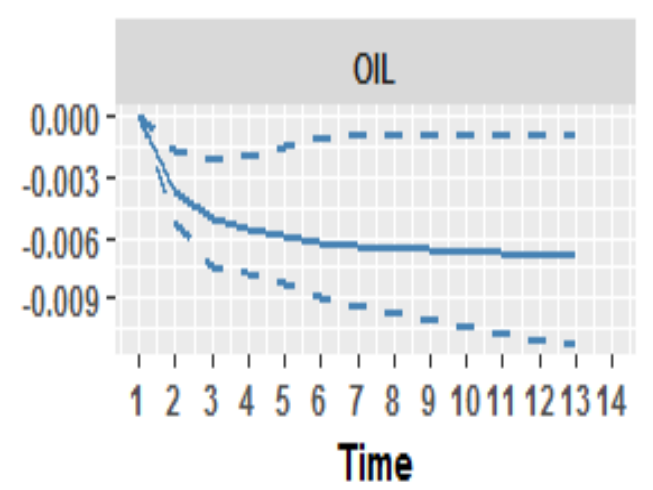

- OlL

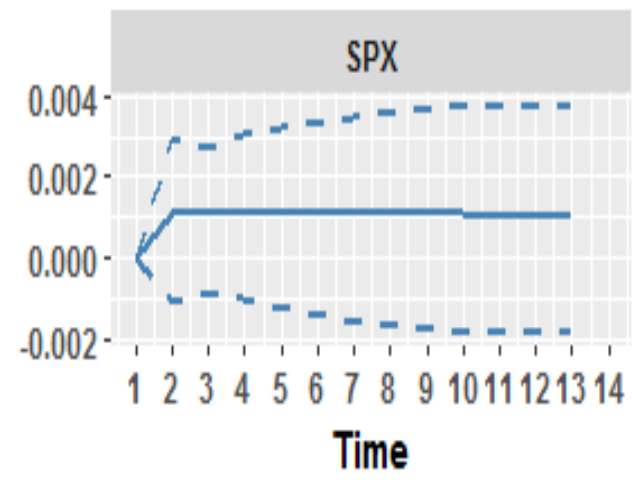

- SPX

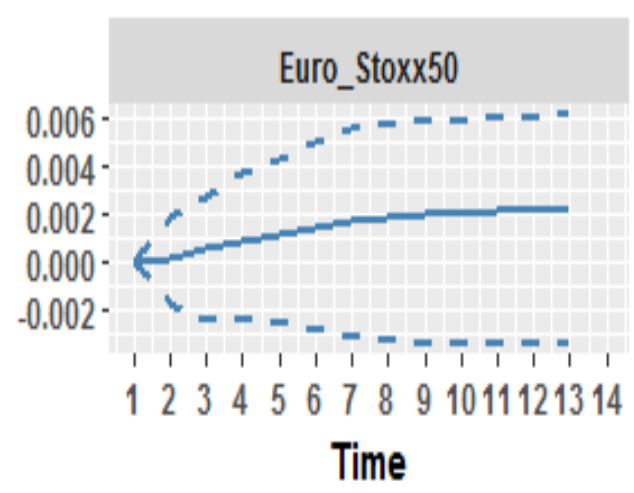

- Euro_Stoxx50

Figure 10: Impulse response function for Peru 


\section{A.7 Results of the backtesting procedure}

Table 12: Correlations of the currency returns

\begin{tabular}{lccccc}
\hline Correlation & BRL & MXN & COP & PEN & CLP \\
\hline BRL & 1.00 & & & & \\
MXN & 0.31 & 1.00 & & & \\
COP & 0.39 & 0.29 & 1.00 & & \\
PEN & 0.16 & 0.11 & 0.34 & 1.00 & \\
CLP & 0.24 & 0.39 & 0.08 & 0.07 & 1.00 \\
\hline
\end{tabular}

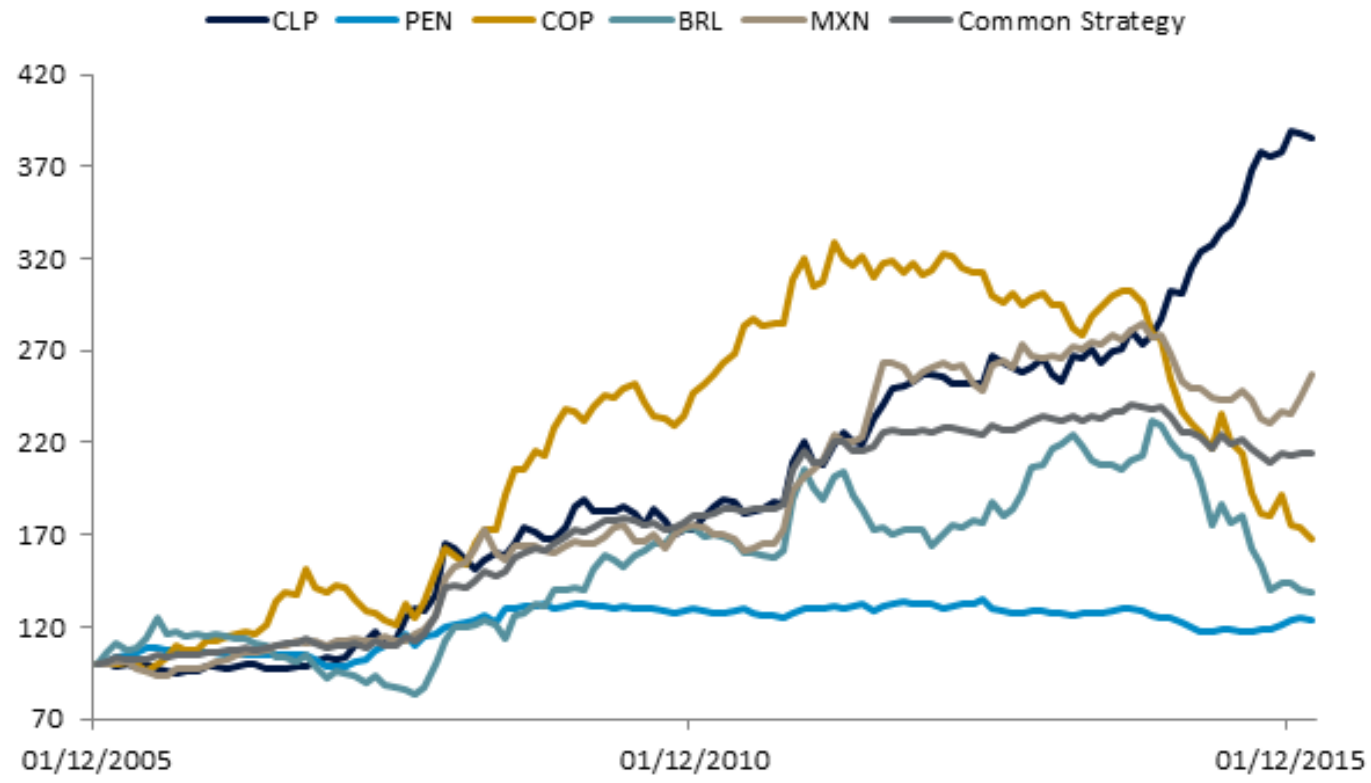

Figure 11: Cumulative returns 

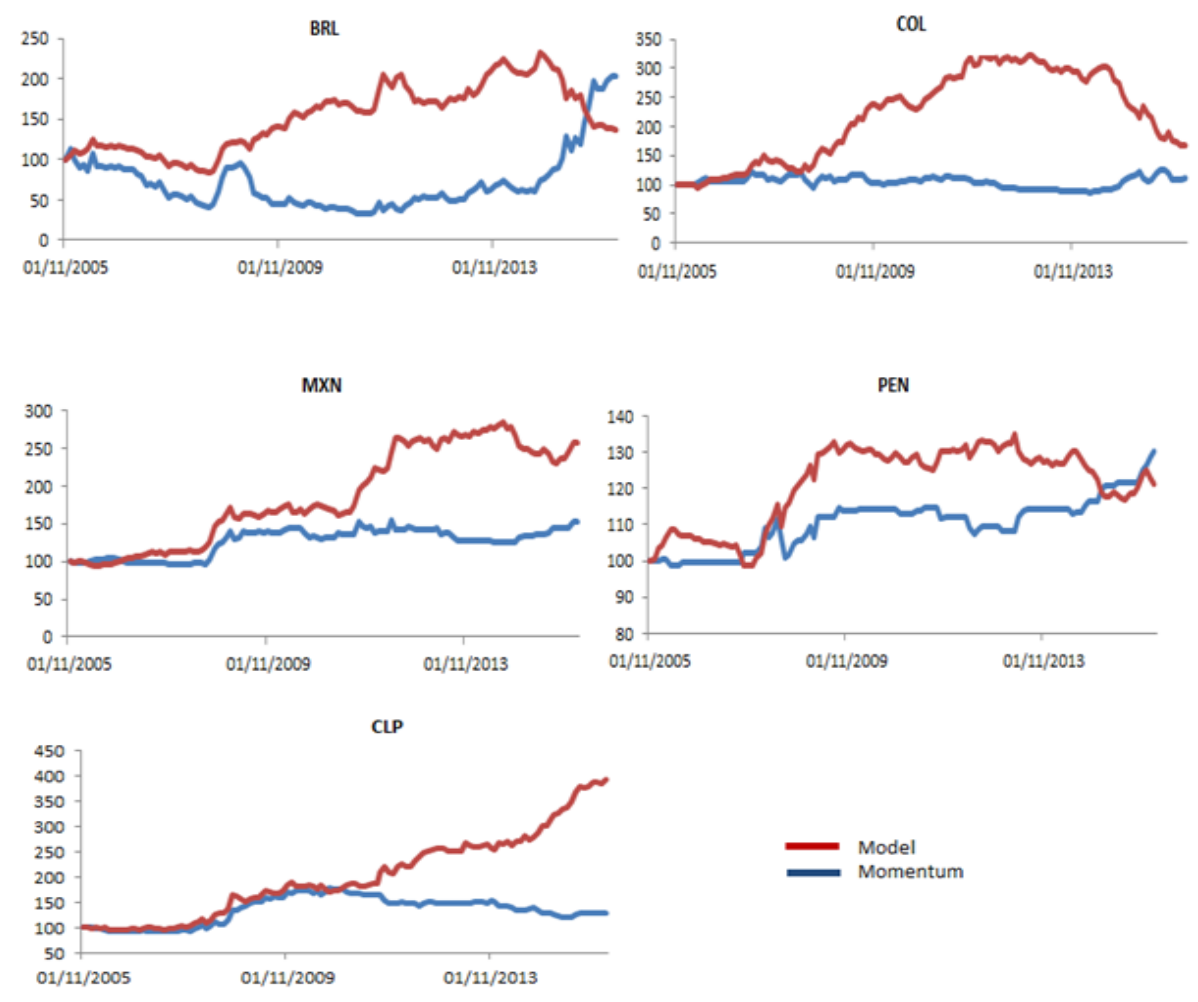

Figure 12: Cumulative returns: Model vs Momentum 